\title{
Intra-neuronal vesicular uptake of catecholamines is decreased in patients with Lewy body diseases
}

\author{
David S. Goldstein, Courtney Holmes, Irwin J. Kopin, Yehonatan Sharabi \\ Clinical Neurocardiology Section, National Institute of Neurological Disorders and Stroke (NINDS), NIH, Bethesda, Maryland, USA.
}

\begin{abstract}
Several neurodegenerative disorders, including Parkinson disease (PD), are characterized by the presence of Lewy bodies - cytoplasmic inclusions containing $\alpha$-synuclein protein aggregates - in the affected neurons. A poorly understood feature of Lewy body diseases is loss of sympathetic nerves in the heart and other organs, manifesting as orthostatic hypotension ( $\mathrm{OH}$; also known as postural hypotension). We asked whether sympathetic denervation is associated with decreased uptake of catecholamines, such as dopamine and norepinephrine, into storage vesicles within sympathetic neurons. We used $6-\left[{ }^{18} \mathrm{~F}\right]$-dopamine $\left({ }^{18} \mathrm{~F}\right.$-DA) to track myocardial uptake and retention of catecholamines. Concurrently, the fate of intra-neuronal ${ }^{18} \mathrm{~F}$-DA was followed by assessment of arterial plasma levels of the ${ }^{18} \mathrm{~F}$-DA metabolite ${ }^{18} \mathrm{~F}$-dihydroxyphenylacetic acid $\left({ }^{18} \mathrm{~F}\right.$-DOPAC). The ratio of myocardial ${ }^{18} \mathrm{~F}$-DA to arterial ${ }^{18} \mathrm{~F}$-DOPAC provided an index of vesicular uptake. Tracer concentrations were measured in patients with $\mathrm{PD}$ with or without orthostatic hypotension (PD+OH, $\mathrm{PD}-\mathrm{No}-\mathrm{OH})$; in patients with pure autonomic failure (PAF, a Lewy body disease without parkinsonism); in patients with multiple system atrophy (MSA, a non-Lewy body synucleinopathy); and in normal controls. Patients with PD+OH or PAF had decreased vesicular ${ }^{18} \mathrm{~F}$-DA uptake and accelerated ${ }^{18} \mathrm{~F}$-DA loss, compared with MSA and control subjects. PD-No-OH patients could be subtyped into one of these categories based on their initial ${ }^{18} \mathrm{~F}$-DA uptake. We conclude that sympathetic denervation in Lewy body diseases is associated with decreased vesicular uptake of neuronal catecholamines, suggesting that vesicular monoamine transport is impaired. Vesicular uptake may constitute a novel target for diagnosis, treatment, and prevention.
\end{abstract}

\section{Introduction}

There is growing recognition that Parkinson disease (PD) is a generalized disorder that, in addition to its well-characterized motor symptoms, involves prominent non-motor manifestations such as dementia, depression, anosmia, and autonomic nervous system failure. Indeed, approximately $90 \%$ of PD patients exhibit signs of failure of one or more components of the autonomic nervous system (1); for example, post mortem neuropathologic studies have demonstrated profound sympathetic denervation within the cardiac tissues of a substantial proportion of PD patients (2). Consistent with this, neuroimaging evidence of cardiac sympathetic denervation has been found in all PD patients with orthostatic hypotension $(\mathrm{PD}+\mathrm{OH}$; also known as $\mathrm{PD}$ with postural hypotension) analyzed (3); however, a substantial proportion of $\mathrm{PD}$ patients without $\mathrm{OH}$ (PD-No-OH) lack evidence of such denervation and have near-normal myocardial neuron uptake of the sympathetic imaging agent $6-\left[{ }^{18} \mathrm{~F}\right]$-dopamine $\left({ }^{18} \mathrm{~F}-\mathrm{DA}\right)(4)$. Since striatal dopaminergic and cardiac sympathetic denervation develop over the course of several years $(5,6)$, understanding the underlying pathologic processes could allow for early identification of individuals at risk for PD and therefore provide an opportunity for neuroprotective intervention.

Although genetic contributions to PD have been identified within familial disease, none account for the vulnerability of the very specific subset of central and peripheral neurons that utilize monoamine neurotransmitters. The selective loss of catecholamin-

Conflict of interest: The authors have delcared that no conflict of interest exists. Citation for this article: J Clin Invest. 2011;121(8):3320-3330. doi:10.1172/JCI45803. ergic striatal dopaminergic and cardiac noradrenergic neurons, however, suggests that a common pathophysiological process may be attacking both tissues.

Dopaminergic neurons in the brain can be studied in vivo using ${ }^{18} \mathrm{~F}$-labeled dihydroxyphenylalanine ( $\left.{ }^{18} \mathrm{~F}-\mathrm{DOPA}\right)$. Although denervation implies a decreased overall ${ }^{18} \mathrm{~F}$-DOPA signal, it does not explain the results of kinetic studies that show faster removal of ${ }^{18} \mathrm{~F}-\mathrm{DOPA}$-derived radioactivity in the putamen of PD patients $(7,8)$. A compensatory increase in pathway traffic to residual dopaminergic terminals, by acting to maintain transmitter delivery to dopamine receptors, has been proposed to explain these data $(7,8)$; however, we hypothesize that, instead, decreased vesicular sequestration results in increased deamination of cytosolic ${ }^{18} \mathrm{~F}$-DA. In this study, we have compared the existing model with our hypothesis using what we believe to be a novel combined neuroimaging-neurochemical approach capable of distinguishing between increased release and decreased vesicular uptake as determinants of accelerated loss of neuronal catecholamines.

Our technique monitors the alternative paths of ${ }^{18} \mathrm{~F}-\mathrm{DA}$, an excellent substrate for uptake into neurons that express cell membrane catecholamine transporters, in cardiac noradrenergic nerves (Figure 1). During a 3-minute i.v. administration of ${ }^{18} \mathrm{~F}-\mathrm{DA}$, plasma levels of the tracer rapidly increase; and during a short interval after termination of the infusion, plasma levels rapidly decline (9). Within this window, sympathetic nerves take up tracer from the circulation via the cell membrane norepinephrine transporter. Cytosolic ${ }^{18} \mathrm{~F}$-DA has only two fates: vesicular uptake via the vesicular monoamine transporter (VMAT) or oxidative deamination by monoamine oxidase (MAO) to form ${ }^{18} \mathrm{~F}$-dihydroxyphenylacetic 

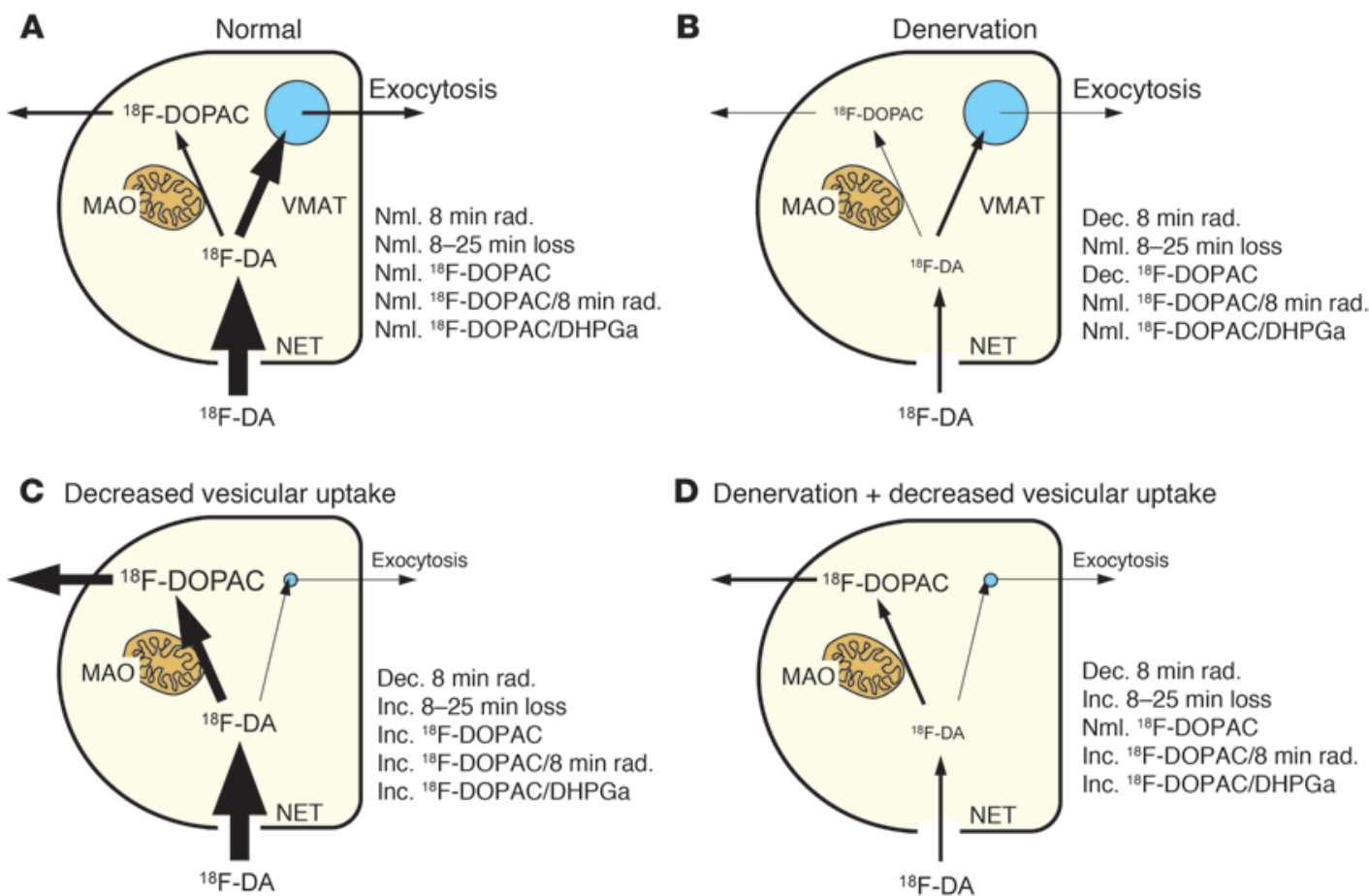

\section{Figure 1}

Concept diagram for the effects of denervation and decreased vesicular sequestration on the uptake and fate of ${ }^{18}$ F-DA. (A) Normally ${ }^{18}$ F-DA is taken up by sympathetic nerves via the cell membrane norepinephrine transporter (NET). Cytosolic ${ }^{18} \mathrm{~F}-\mathrm{DA}$ mainly undergoes vesicular uptake via the VMAT, with subsequent loss of radioactivity via exocytotic release, and to a lesser extent undergoes oxidative deamination catalyzed by monoamine oxidase to form ${ }^{18} \mathrm{~F}$-DOPAC. (B) Reduced sympathetic innervation decreases total neuronal uptake of ${ }^{18} \mathrm{~F}-\mathrm{DA}$, resulting in decreased initial myocardial radioactivity. The rate of loss of radioactivity is normal. (C) Reduced VMAT activity decreases radioactivity because augmented ${ }^{18} \mathrm{~F}-\mathrm{DOPAC}$ production accelerates loss of cytosolic ${ }^{18} \mathrm{~F}-\mathrm{DA}$. (D) The combination of decreased sympathetic innervation and reduced VMAT activity decreases initial radioactivity, accelerates its loss, and increases ${ }^{18} \mathrm{~F}-\mathrm{DOPAC}$ production. Dec., decreased; Inc., increased; Nml., normal; rad., myocardial ${ }^{18} \mathrm{~F}-\mathrm{DA}$-derived radioactivity.

acid $\left({ }^{18} \mathrm{~F}-\mathrm{DOPAC}\right)$, which is then rapidly extruded from the cell. Vesicular uptake normally predominates over oxidative deamination (Figure 1A) (10-13). Radioactivity is thus retained in neurons due to (a) effective reuptake by the VMAT of any ${ }^{18} \mathrm{~F}-\mathrm{DA}$ that leaks passively into the cytosol, preventing its metabolism by MAO; and (b) neuronal reuptake of any released vesicular ${ }^{18} \mathrm{~F}-\mathrm{DA}$, preventing its extra-neuronal metabolism or entry into the circulation.

The ratio of retained ${ }^{18} \mathrm{~F}$-DA to released ${ }^{18} \mathrm{~F}$-DOPAC acts as an index of vesicular transport (IVT). Neuronal degeneration alone would decrease both measures proportionately (Figure 1B), yielding lower absolute signals but with a constant IVT. In contrast, decreased VMAT activity would be expected to diminish retention of ${ }^{18} \mathrm{~F}-\mathrm{DA}$ and increase release of ${ }^{18} \mathrm{~F}$-DOPAC (Figure 1C), decreasing the IVT. A combination of the two deficits would produce a decreased radioactive signal as well as a low IVT (Figure 1D).

Using this method, we compared patients with PD and patients with other diseases manifest by varying overlapping symptoms (Figure 2) to determine whether the diseases involve cardiac sympathetic denervation or abnormal neuronal catecholamine handling. Two rare patients with $\mathrm{PD}+\mathrm{OH}-$ one with an A53T mutation of the $\alpha$-synuclein gene that is known as PARK1 and one with triplication of the normal $\alpha$-synuclein gene that is known as PARK 4 - were tested to look for correlation with $\alpha$-synucleinopathy. To determine whether changes were more generally characteristic of Lewy body diseases, we tested patients with pure autonomic failure (PAF). PAF is a rare but scientifically important Lewy body disease (14) that features cardiac and extracardiac sympathetic denervation (15) and neurogenic $\mathrm{OH}$ without parkinsonism. In contrast, multiple system atrophy (MSA) is a non-Lewy body synucleinopathy that can resemble $\mathrm{PD}+\mathrm{OH}$ clinically (16). In MSA, aggregates of $\alpha$-synuclein are characteristically found in glial cytoplasmic inclusions (17); however, most MSA patients have intact sympathetic noradrenergic innervation (18). As we describe here, application of our ${ }^{18} \mathrm{~F}-\mathrm{DA}$ tracer method to these different patient groups has provided insight into the pathogenesis of cardiac sympathetic denervation in PD.

\section{Results}

Clinical characteristics of subject groups. The clinical characteristics of and differences between subject groups are summarized in Table 1. $\mathrm{PD}+\mathrm{OH}$ and $\mathrm{PD}-\mathrm{No}-\mathrm{OH}$ groups did not differ in duration of motor symptoms or scores on the Unified Parkinson's Disease Rating Scale (UPDRS). $\mathrm{PD}+\mathrm{OH}$ patients were also comparable to MSA patients in terms of autonomic symptoms and scores on the UPDRS.

Normal kinetics of ${ }^{18} \mathrm{~F}$-DA uptake and decline. Intravenous administration of ${ }^{18} \mathrm{~F}$-DA produced immediate loading of the sympathetic nerves with ${ }^{18} \mathrm{~F}-\mathrm{DA}$-derived radioactivity (Figure $3 \mathrm{~A}$ ). By the end of a 3-minute infusion, radioactivity in the left ventricular myocardium exceeded that in the left ventricular chamber, reflecting rapid uptake of ${ }^{18} \mathrm{~F}-\mathrm{DA}$ from the circulation (Figure 3, A-C). Arte- 


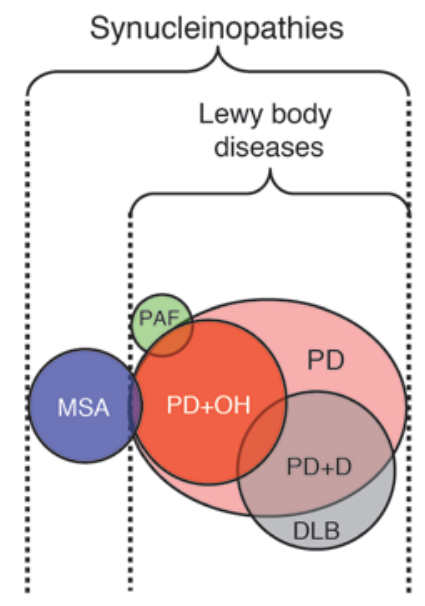

rial plasma levels of ${ }^{18} \mathrm{~F}$-DOPAC increased concurrently (Figure $3 \mathrm{D})$, implying extremely rapid metabolism of ${ }^{18} \mathrm{~F}$-DA and release of the metabolite into the extracellular fluid and plasma. No further delivery of ${ }^{18} \mathrm{~F}-\mathrm{DA}$ was apparent after 8 minutes from the initiation of the infusion (Figure 3A).

After tissue loading, ${ }^{18} \mathrm{~F}-\mathrm{DA}$-derived radioactivity declined in a mono-exponential manner $(r=0.999$, Figure $3 \mathrm{~A})$ that was described by the slope of a logarithmic line of best fit between 8 and 25 minutes from initiation. That the practically instantaneous myocardial uptake and metabolism of ${ }^{18} \mathrm{~F}-\mathrm{DA}$ take place mainly in sympathetic nerves was demonstrated by pretreatment with desipramine, which specifically blocks neuronal monoamine uptake. Desipramine pretreatment markedly decreased myocardial ${ }^{18} \mathrm{~F}$-DA-derived radioactivity, and concomitantly attenuated plasma ${ }^{18} \mathrm{~F}$-DOPAC responses (Figure $3, \mathrm{~A}-\mathrm{D}$, open circles).

Patient groups differ in ${ }^{18} \mathrm{~F}$-DA uptake. The compared patient groups did not differ in arterial ${ }^{18} \mathrm{~F}$-DA-derived radioactivity from the left ventricular chamber, indicating equivalent initial ${ }^{18} \mathrm{~F}-\mathrm{DA}$ exposure (Figure 4A). Radioactivity in the liver, reflecting mainly non-neuronal uptake of ${ }^{18} \mathrm{~F}-\mathrm{DA}$ or its metabolites, was used as a control measure of nonspecific signal. Hepatic ${ }^{18} \mathrm{~F}-\mathrm{DA}$ was moderately greater at the 8 -minute time point in all patient groups $-\mathrm{PD}+\mathrm{OH}(8,491 \pm 256 \mathrm{nCi}-\mathrm{kg} /$ cc-mCi), PAF $(8,682 \pm 504 \mathrm{nCi}-\mathrm{kg} / \mathrm{cc}-\mathrm{mCi})$, and MSA $(8,523 \pm 228 \mathrm{nCi}-\mathrm{kg} / \mathrm{cc}-\mathrm{mCi})-$ compared with the normal group $(7,398 \pm 249 \mathrm{nCi}-\mathrm{kg} /$ cc-mCi; $P=0.002, P=0.013, P=0.0008$, respectively) (Figure 4B); however, this was in marked contrast to the clear and substantial differences in myocardial radioactivity among groups, where signals diverged immediately upon tracer administration and persisted throughout the study (Figure 4C). Low levels of radioactivity were observed in the $\mathrm{PD}+\mathrm{OH}$ and PAF groups, whereas the MSA group had signals similar to those of normal controls (Figure 4C).

Normalizing the myocardial signals against hepatic (Figure 4D) or arterial (equivalent to left ventricular chamber; Figure 4E) radioactivity revealed a striking divergence among the groups. In the normal and MSA groups, mean myocardial/

\section{Figure 2}

Venn diagram showing relationships among some $\alpha$-synucleinopathies. Lewy body diseases include PD, PAF, and dementia with Lewy bodies (DLB). The diagram is based on (a) PD being the most prevalent Lewy body disease; (b) PAF being a rare disease; (c) orthostatic hypotension $(\mathrm{OH})$ occurring in a substantial minority of PD patients; (d) DLB overlapping considerably with PD plus dementia (PD+D); (e) MSA being a non-Lewy body form of $\alpha$-synucleinopathy that involves $\alpha$-synuclein deposition in glial cytoplasmic inclusions, although (f) a small minority of MSA patients also have Lewy bodies; and (g) some patients initially thought to have PAF proving to have pre-motor $\mathrm{PD}+\mathrm{OH}$. Reproduced with permission from Journal of the Neurological Sciences (57). liver and myocardial/plasma ratios were effectively identical, yet they were dramatically increased at all time points when compared with $\mathrm{PD}+\mathrm{OH}$ and $\mathrm{PAF}$ groups, which were themselves similar (Figure 4, D and $\mathrm{E}$ ). The PD-No-OH subgroup had a distinctive intermediate level of ${ }^{18} \mathrm{~F}-\mathrm{DA}$ uptake, with resultant signal ratios falling midway between the normal/MSA and PD+OH/PAF results (Figure 4, C-E).

Accelerated decline in myocardial ${ }^{18} \mathrm{~F}-\mathrm{DA}$ signal. Assessment of the kinetics of the decline in radioactive signal between 8 and 25 minutes provided a second measure of neuronal catecholamine handling by the sympathetic nerves in the myocardium. Baseline myocardial loading was assessed after 8 minutes (Figure 4C, group; Figure 5A, individuals), and the rate of signal reduction calculated for the 8- to 25-minute window (Figure 5B, individuals). Notably, the PD-No-OH data visibly organized into two distinct subpopulations of high versus low baseline loading and rates of signal decline (Figure 5, A and B), reflecting the intermediate mean levels observed previously (Figure 4, C-E).
Table 1

Clinical characteristics of subject groups

\begin{tabular}{lccccc}
\hline & & & & & \\
& PD+OH & PD-No-OH & MSA & PAF & Normal \\
Age (yr) & $70 \pm 1^{\text {A }}$ & $59 \pm 2$ & $61 \pm 1^{\mathrm{B}}$ & $63 \pm 3$ & $47 \pm 3$ \\
Male/female & $27 / 11$ & $30 / 8$ & $35 / 24$ & $12 / 6$ & $34 / 12$ \\
Light-colored skin (\%) & 92 & 95 & 80 & 100 & 78 \\
Ashkenazi (\%) & 24 & 13 & 10 & 6 & \\
Age at motor onset (yr) & $60 \pm 2^{\mathrm{C}}$ & $52 \pm 2$ & $56 \pm 1$ & & \\
Time to study (yr) & $9 \pm 2$ & $7 \pm 1$ & $4 \pm 1^{\mathrm{B}}$ & \\
Bradykinesia (\%) & 100 & 100 & $68^{\mathrm{B}}$ & \\
Rigidity (\%) & 91 & 93 & $56^{\mathrm{B}}$ & \\
Resting tremor (\%) & 65 & 80 & $7^{\mathrm{B}}$ & \\
Levodopa resp. (\%) & 87 & 100 & $39 \mathrm{~B}$ & & \\
UPDRS (off Rx) & $49 \pm 7$ & $44 \pm 8$ & $53 \pm 6$ & & \\
Slurred speech (\%) & 21 & 20 & $74^{\mathrm{B}}$ & & \\
Orthostatic intol. (\%) & $80^{\mathrm{A}}$ & 11 & 43 & 100 & \\
Erectile failure (\%) & $85^{\mathrm{C}}$ & 25 & 89 & 100 & \\
Constipation (\%) & $82^{\mathrm{D}}$ & 47 & 81 & 80 & \\
Dec. sweating (\%) & $44^{\mathrm{D}}$ & 0 & 30 & 60 & \\
Urinary symptoms (\%) & 91 & 76 & 94 & 40 & \\
& & & & &
\end{tabular}

${ }^{A} P<0.001, P D+O H$ versus $P D-N o-O H . ~ B P<0.001, P D+O H$ versus MSA. ${ }^{C} P<0.01$, $\mathrm{PD}+\mathrm{OH}$ versus $\mathrm{PD}-\mathrm{No}-\mathrm{OH}$. ${ }^{\mathrm{P}} P<0.05, \mathrm{PD}+\mathrm{OH}$ versus $\mathrm{PD}-\mathrm{No}-\mathrm{OH}$. intol., intolerance; resp., responsiveness; Dec., decreased. 


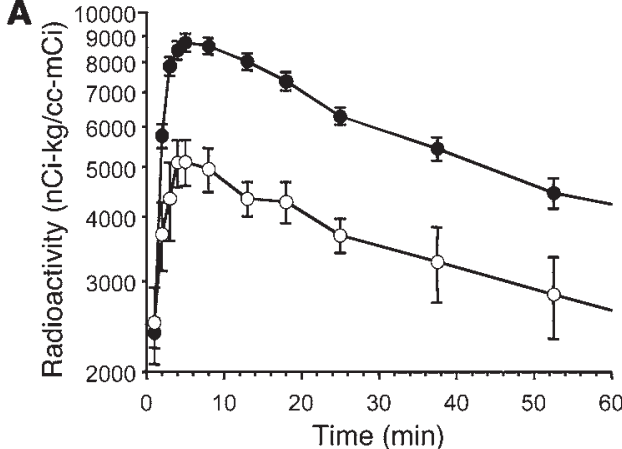

C

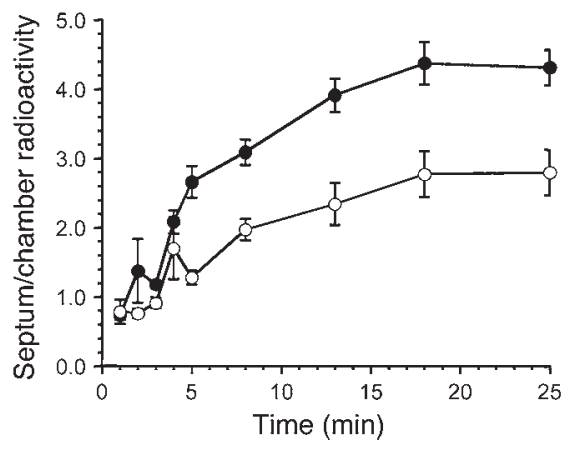

B

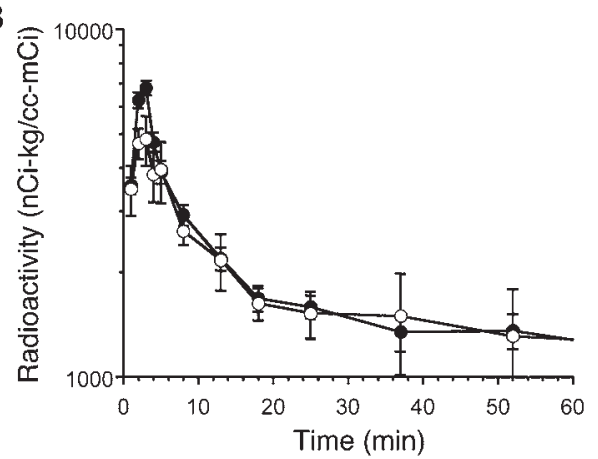

D

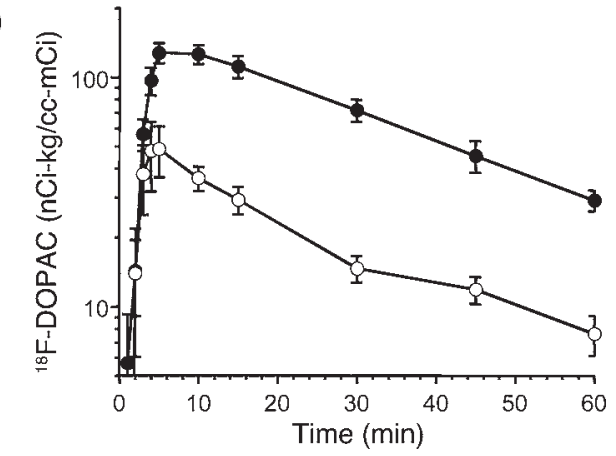

Figure 3

Effects of desipramine on neuronal uptake and intra-neuronal metabolism of ${ }^{18} \mathrm{~F}-\mathrm{DA}$. Filled circles show data from untreated healthy controls, and open circles show data from controls pretreated with $125 \mathrm{mg}$ of oral desipramine about 2 hours before ${ }^{18} \mathrm{~F}-\mathrm{DA}$ administration. (A) Mean $( \pm$ SEM) concentrations of interventricular septal myocardial ${ }^{18} \mathrm{~F}-\mathrm{DA}$-derived radioactivity as a function of time after 3-minute constant i.v. infusion of ${ }^{18} \mathrm{~F}$-DA. (B) Mean concentrations of ${ }^{18} \mathrm{~F}$-DA-derived radioactivity in the left ventricular chamber. (C) Mean ratios of myocardial to left ventricular chamber radioactivity. (D) Mean arterial plasma concentrations of ${ }^{18} \mathrm{~F}$-DOPAC.
With the PD-No-OH group additionally partitioned as "low radiation" (Low rad.) and "normal radiation" ( $\mathrm{Nml}$. rad.) based on the 8-minute base signals, the patient data were used to assess the interaction of initial uptake with signal decline. A logarithmic regression of the baseline loading versus signal decline values produced a strong correlation of high significance $(r=0.46, P<0.0001$; Figure $5 \mathrm{C}$, individuals). The separation of phenotypes was particularly striking when analyzed by group means, with $\mathrm{PD}+\mathrm{OH}$ and $\mathrm{PAF}$ groups having low uptake and rapid signal loss, whereas MSA and normal groups had high initial uptake with slower decline (Figure 5D). Instead of appearing as an intermediate phenotype, PD-No$\mathrm{OH}$ patients cleanly separated with the other conditions, with a low initial signal predicting a $\mathrm{PD}+\mathrm{OH} / \mathrm{PAF}$ result and a high initial signal predicting an MSA/normal result (Figure 5D).

Notably, the patient with PARK1 (black circle in Figure 5D) and the patient with PARK4 (black square in Figure 5D) both had low initial myocardial ${ }^{18} \mathrm{~F}-\mathrm{DA}$ after 8 minutes and high rates of loss of signal, consistent with the other patients in the $\mathrm{PD}+\mathrm{OH}$ group.

Higher relative ${ }^{18} \mathrm{~F}-D O P A C$ indicates lower VMAT activity. Despite evidence of severely restricted myocardial uptake of ${ }^{18} \mathrm{~F}-\mathrm{DA}$ in $\mathrm{PD}+\mathrm{OH}$ and PAF patients (Figure 5A), those same patients had increased $(\mathrm{PD}+\mathrm{OH})$ or normal $(\mathrm{PAF})$ arterial plasma levels of the ${ }^{18} \mathrm{~F}-\mathrm{DA}$ metabolite ${ }^{18} \mathrm{~F}-\mathrm{DOPAC}$ (Figure $\left.6 \mathrm{~A}\right)$. The ratio of the two signals $\left({ }^{18} \mathrm{~F}-\mathrm{DA} /\right.$ ${ }^{18} \mathrm{~F}$-DOPAC) constituted the IVT for cytosolic ${ }^{18} \mathrm{~F}$-DA. By this measure, $\mathrm{PD}+\mathrm{OH}$ and $\mathrm{PAF}$ groups exhibited vastly reduced VMAT activity after 8 minutes compared with the normal and MSA groups $\left(\chi^{2}=24, P<10^{-6}\right.$; Figure 6, B and C). This deficit persisted throughout the time course of the study, with group mean index values falling rapidly before stabilizing around 10 minutes at $10 \%$ and $30 \%$ of normal for $\mathrm{PD}+\mathrm{OH}$ and PAF groups, respectively (Figure 6D). The IVT and rate of radioactivity loss were negatively correlated, and the distribution of values among disease groups was strongly correlated with the presence of Lewy body disease $\left(\chi^{2}=40, P<0.001\right.$; Figure 6E).
An alternative measure of vesicular uptake of cytosolic ${ }^{18} \mathrm{~F}-\mathrm{DA}$ in the whole body is based on the relationship between plasma ${ }^{18} \mathrm{~F}-\mathrm{DOPAC}$ and the main neuronal metabolite of norepinephrine, dihydroxyphenylglycol (DHPG). Under resting conditions, arterial plasma DHPG (DHPGa) indicates the overall turnover of vesicular stores of norepinephrine in sympathetic nerves (19). Decreased vesicular uptake (adjusted for sympathetic denervation) would thus be associated with low DHPGa and increased ${ }^{18} \mathrm{~F}-\mathrm{DOPAC}$, with their ratio forming an index of vesicular ${ }^{18} \mathrm{~F}$-DA sequestration. The $\mathrm{PD}+\mathrm{OH}$ and $\mathrm{PAF}$ groups had significantly lower ratios of DHPGa to ${ }^{18} \mathrm{~F}-\mathrm{DOPAC}$ than MSA or control groups (Figure 7, A-C). Across subject groups, decreased vesicular uptake was associated with accelerated loss of myocardial ${ }^{18} \mathrm{~F}$-DA-derived radioactivity (Figure 7D).

ANCOVA. For the rate of loss of intra-neuronal catecholamines and for vesicular uptake, the group $\times$ age interaction terms of analyses of covariance (ANCOVAs) were not statistically significant $(F=1.584, P=0.1807 ; F=0.107, P=0.9970)$. For 8 -minute radioactivity, the group $\times$ age interaction term attained statistical significance $(F=4.395, P=0.0020)$. This was because of a positive correlation between 8 -minute radioactivity and age in the normal group $(r=0.41, P=0.005)$. When the ANCOVA for 8 -minute radioactivity was repeated for the patient groups while excluding the normal group, then the group $\times$ age interaction term was not statistically significant $(F=1.008, P=0.3910)$, and the post-hoc tests confirmed decreased neuronal uptake in the Lewy body diseases (PD+OH, PD-No-OH, and PAF) compared with the MSA group $(P<0.0001$ each). Therefore, the major results were not associated with other clinical disparities between disease groups.

\section{Discussion}

In this study, patients with PD or PAF had accelerated loss of catecholamines in cardiac sympathetic nerves. Although both diseases are known to be associated with cardiac sympathetic denervation 

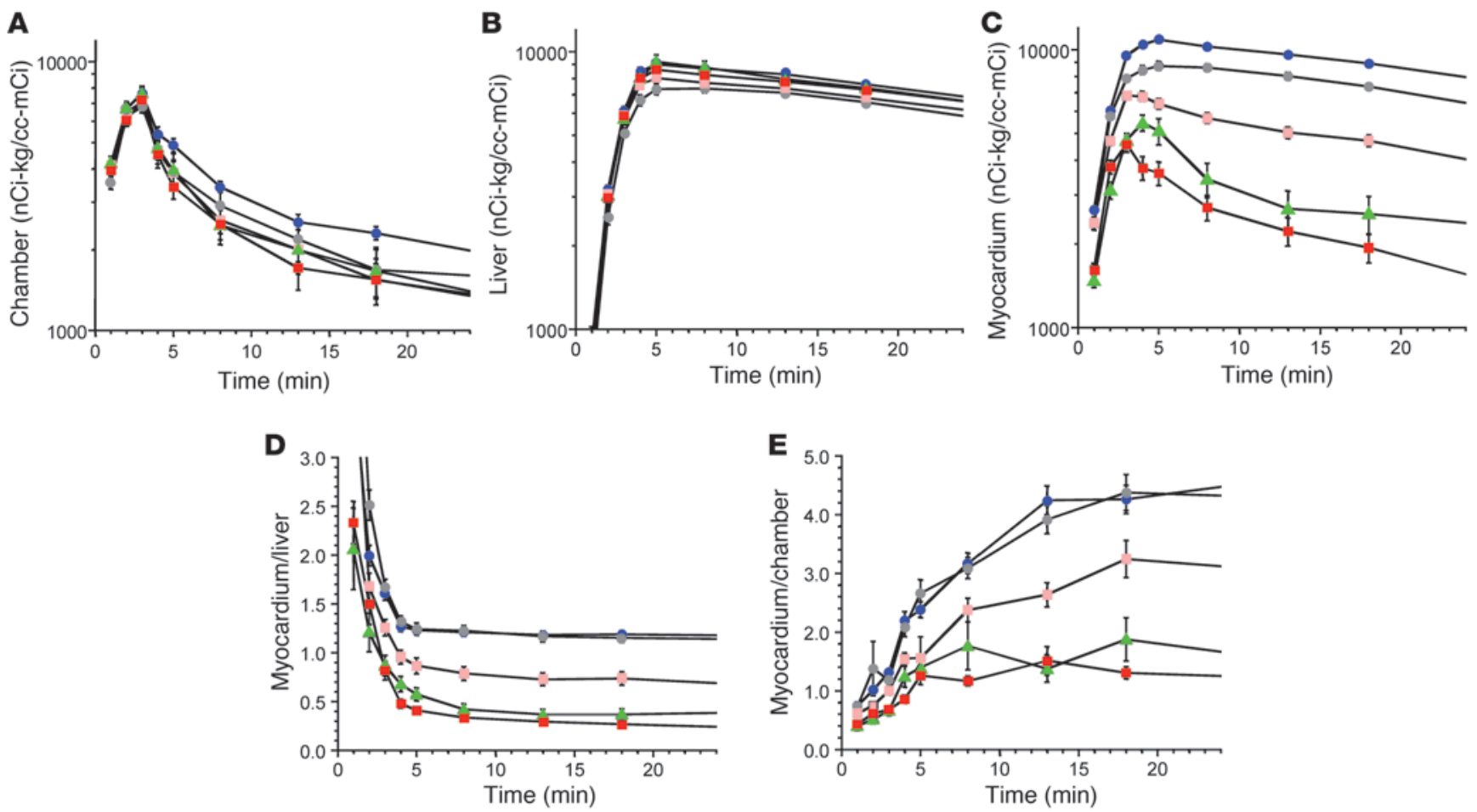

\section{Figure 4}

Mean $\left( \pm\right.$ SEM) concentrations of ${ }^{18} \mathrm{~F}-\mathrm{DA}$-derived radioactivity in patient groups. (A) Left ventricular chamber radioactivity. (B) Liver radioactivity. (C) Interventricular septal myocardial radioactivity. (D) Ratio of myocardium/liver radioactivity. (E) Ratio of myocardium/left ventricular chamber radioactivity. Red, PD+OH; pink, PD-No-OH; blue, MSA; green, PAF; gray, normal control subjects.

(20), loss of neurons in itself is insufficient to explain this pattern. Measurement of arterial plasma concentrations of ${ }^{18} \mathrm{~F}$-DOPAC was the key to quantifying the alternate dispositions of ${ }^{18} \mathrm{~F}-\mathrm{DA}$. Collectively, our findings suggest that decreased vesicular uptake underlies the accelerated loss of intra-neuronal catecholamines in Lewy body diseases (Figure 8).

${ }^{18} \mathrm{~F}$-DA tracking in $\alpha$-synucleinopathies. PD and PAF are characterized by $\alpha$-synuclein deposits in Lewy bodies and Lewy neurites (21). In contrast, MSA is a non-Lewy body synucleinopathy in which $\alpha$-synuclein deposition occurs in glial cells (17). Among $\alpha$-synucleinopathies, it is the Lewy body diseases that are specifically associated with accelerated loss of intra-neuronal catecholamines. Normal volunteers treated with desipramine to block catecholamine uptake had decreased myocardial ${ }^{18} \mathrm{~F}-\mathrm{DA}$ without alteration of the rate of removal of residual radioactivity. Similarly, normal findings in MSA were consistent with the view that in MSA autonomic failure results from impaired control of outflows in intact sympathetic nerves (22). In contrast, only patients with PD or PAF had evidence for accelerated loss of catecholamines from cardiac sympathetic nerves.

Among individuals with evidence for accelerated loss of radioactivity and decreased vesicular uptake, all had $\mathrm{PD}+\mathrm{OH}$ or PAF; whereas among subjects with normal rates of signal loss and normal vesicular uptake, all had MSA or were normal controls. Importantly, patients with rare, dominantly inherited $\mathrm{PD}+\mathrm{OH}$ from mutation of the $\alpha$-synuclein gene (PARK1) or from triplication of the normal $\alpha$-synuclein gene (PARK4) had high rates of myocardial ${ }^{18} \mathrm{~F}$-DA loss, comparable to patients with sporadic $\mathrm{PD}+\mathrm{OH}$. This suggests that $\alpha$-synucleinopathy in catechol- aminergic neurons may contribute to accelerated loss of intraneuronal catecholamines.

The measurement of arterial plasma concentrations of ${ }^{18} \mathrm{~F}-\mathrm{DOPAC}$ was critical to quantifying the alternate dispositions of ${ }^{18} \mathrm{~F}-\mathrm{DA}$. Values for IVT were decreased in $\mathrm{PD}+\mathrm{OH}$ and PAF patients compared with those in MSA and in untreated and desipramine-treated normal volunteers. This provided in vivo evidence for impaired VMAT activity. Arterial DHPG divided by peak ${ }^{18} \mathrm{~F}-\mathrm{DOPAC}$, an index of vesicular uptake in the body as a whole, was also clearly lower in the $\mathrm{PD}+\mathrm{OH}$ and $\mathrm{PAF}$ than in the MSA and normal groups. In PAF, decreased neuronal uptake (decreasing $\left.{ }^{18} \mathrm{~F}-\mathrm{DOPAC}\right)$ was counterbalanced by decreased vesicular uptake (increasing ${ }^{18} \mathrm{~F}-\mathrm{DOPAC}$ ).

${ }^{18} \mathrm{~F}$-DA scanning and assays of plasma ${ }^{18} \mathrm{~F}$-DOPAC are currently only feasible at the NIH Clinical Center. To replicate the present results at other centers may require development of alternative clinical means to assess vesicular uptake. For instance, because of the vesicular localization of dopamine-beta-hydroxylase, after administration of tracer-labeled dopamine a high ratio of labeled dopamine metabolites to labeled norepinephrine metabolites in urine would point to decreased vesicular uptake.

Mechanism of catecholamine loss. Several studies have suggested that $\alpha$-synucleinopathy in catecholaminergic neurons may interfere with vesicular dopamine recycling. Specifically, overexpression of $\alpha$-synuclein increased cytosolic dopamine concentrations (23) and stable transfection of $\alpha$-synuclein into SHSY5Y cells decreased vesicular uptake (24), while protofibrillar A53T mutant $\alpha$-synuclein permeabilized vesicles (25). Neuroimaging studies have previously noted decreased binding of ligands for VMAT in PD, with the decreased binding taken as evidence for 

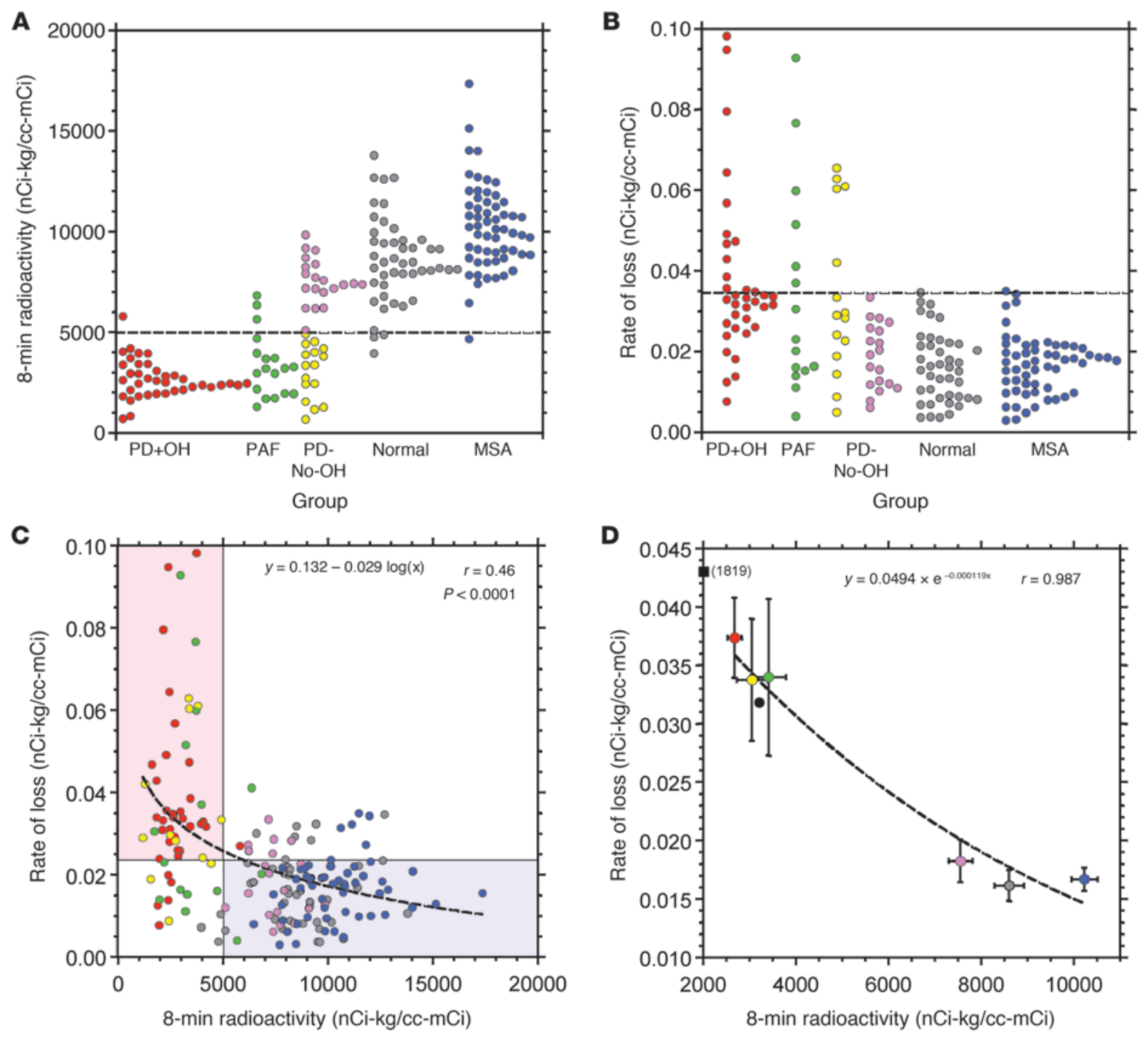

\section{Figure 5}

Individual and group mean values for initial ${ }^{18} \mathrm{~F}-\mathrm{DA}$-derived radioactivity and rates of decline. (A) Initial radioactivity for individuals. (B) Rates of loss of radioactivity for individuals. (C) Scatter plot of individual values for rates of loss versus initial radioactivity. Shaded rectangles highlight regions of (top left) decreased initial radioactivity plus increased loss in patients with Lewy body diseases (pink) or (bottom right) normal initial radioactivity and normal rates of loss in patients with MSA. Dashed line represents the logarithmic equation of best fit. (D) Scatter plot of individual values for rates of loss versus initial radioactivity. Mean $( \pm$ SEM) slopes expressed as a function of mean radioactivity at 8 minutes. Red, PD+OH; yellow, PD without OH and with low ${ }^{18} \mathrm{~F}-\mathrm{DA}$ (PD-No-OH Low rad.); magenta, PD without OH and with normal ${ }^{18} \mathrm{~F}-\mathrm{DA}$ (PD-No-OH $\mathrm{Nml}$. rad.); blue, MSA; green, PAF; gray, normal control subjects. Black circle, $\mathrm{PD}+\mathrm{OH}(\mathrm{PARK} 1)$ patient; black square, $\mathrm{PD}+\mathrm{OH}(\mathrm{PARK} 4)$ patient. "(1819)" indicates the 8-minute radioactivity for that data point.

the loss of neurons (26). Our results suggest that vesicular uptake itself may be impaired.

Impairment of vesicular uptake is likely to involve a reduction in the presence or activity of VMAT. A recent report noted decreased expression of the type 2 VMAT gene in platelets from PD patients (27), although it is unclear whether this pattern is shared in cardiac sympathetic neurons. There are several other ways that vesicular uptake could be compromised. For example, axoplasmic transport delivers key vesicular proteins from their site of synthesis in the cell body to the terminals; thus, vesicular uptake could also be reduced by structural or functional abnormalities of axonal trafficking that decrease the number of vesicles available. Alternatively, cell mem- brane and vesicular monoamine transport are energy-requiring processes $(28,29)$, and intrinsic errors of mitochondrial function or metabolic insults posed by exogenous toxins could result in decreased neuronal uptake and vesicular sequestration. Moving forward, bases for the deficit in vesicular ${ }^{18} \mathrm{~F}-\mathrm{DA}$ uptake will need to be resolved.

Study limitations. The use of arterial ${ }^{18} \mathrm{~F}-\mathrm{DOPAC}$ as an indirect measure of vesicular uptake of ${ }^{18} \mathrm{~F}-\mathrm{DA}$ in sympathetic nerves was critical to this study. Medications, individual differences in catechol metabolism, and heterogeneity of noradrenergic denervation among organs might influence circulating ${ }^{18} \mathrm{~F}$-DOPAC levels. In addition, ${ }^{18} \mathrm{~F}$-DOPAC produced from ${ }^{18} \mathrm{~F}-\mathrm{DA}$ in non-neuronal cells is converted efficiently to ${ }^{18} \mathrm{~F}$-homovanillic acid by catechol- 
A
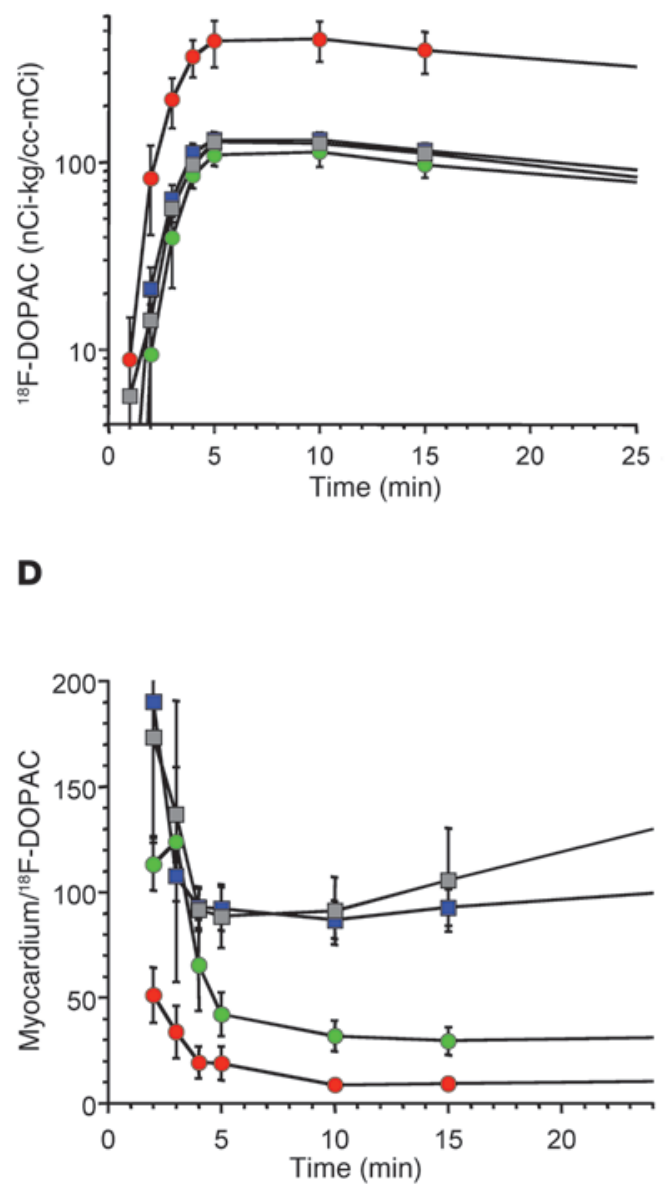
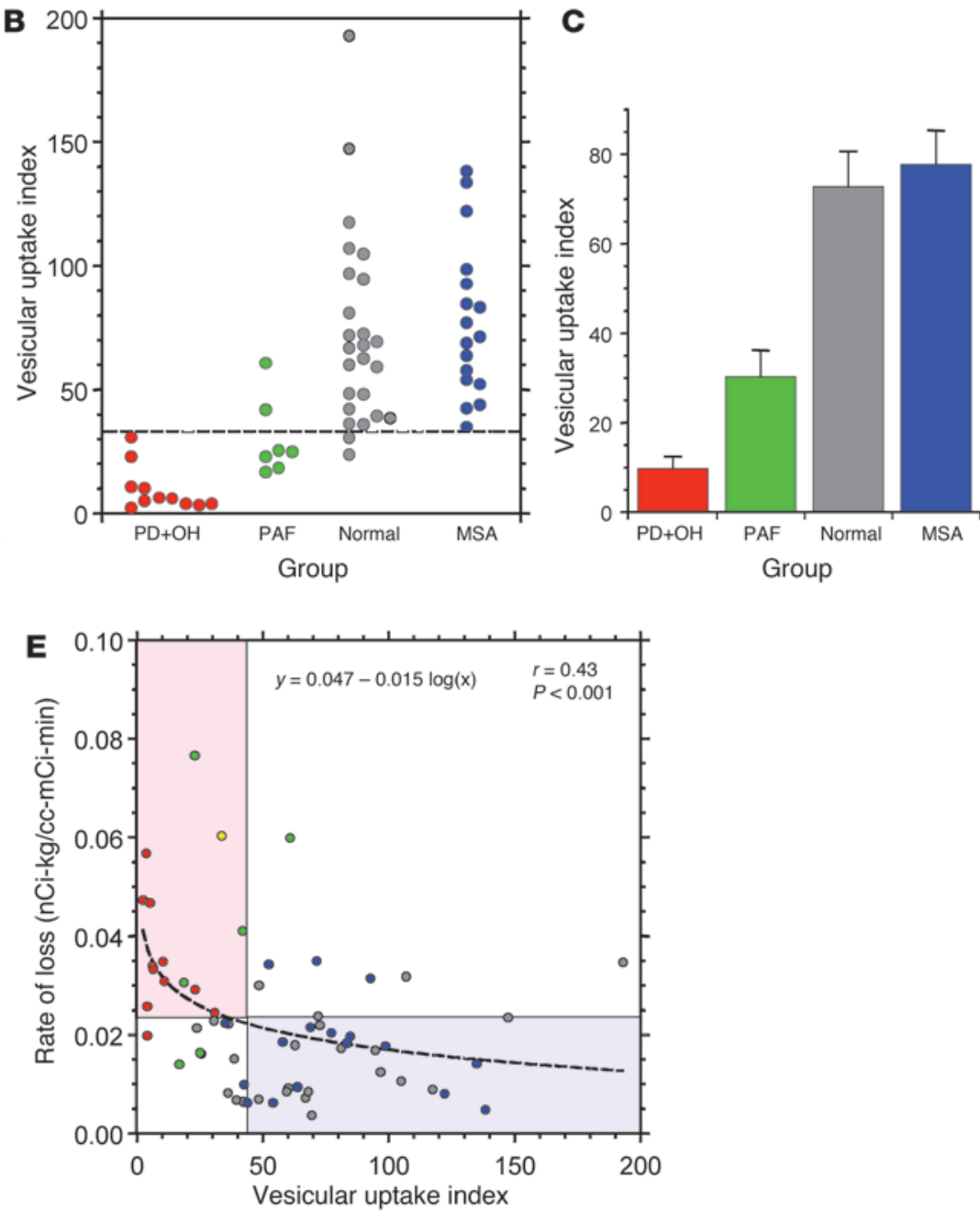

Figure 6

Intra-neuronal metabolism and myocardial vesicular uptake of ${ }^{18} \mathrm{~F}-\mathrm{DA}$. (A) Mean $\left({ }^{\mathrm{SSEM}}\right)$ arterial plasma concentrations of ${ }^{18} \mathrm{~F}-\mathrm{DOPAC}$ as a function of time. (B) Vesicular uptake index (initial radioactivity divided by peak ${ }^{18} \mathrm{~F}$-DOPAC) for individuals. (C) Group mean values for vesicular uptake index. (D) Group mean values for the ratio of myocardial radioactivity to concurrent plasma ${ }^{18} \mathrm{~F}-\mathrm{DOPAC}$ as a function of time. (E) Individual values for rate of loss of radioactivity versus vesicular uptake index. Shaded rectangles highlight regions of (top left) decreased initial radioactivity plus increased loss in patients with Lewy body diseases (pink) or (bottom right) normal initial radioactivity and normal rates of loss in patients with MSA. Dashed line represents the logarithmic equation of best fit. Red, PD+OH; yellow, PD-No-OH Low rad.; blue, MSA; green, PAF; gray, normal control subjects.

$O$-methyltransferase, such that low catechol-O-methyltransferase activity might increase plasma ${ }^{18} \mathrm{~F}$-DOPAC; however, there is no evidence that either PD or PAF is associated with polymorphism of the catechol-O-methyltransferase gene (30); and the ratio of plasma normetanephrine to DHPG, an index of catechol-O-methyltransferase activity, is about the same in MSA as in PAF and $\mathrm{PD}+\mathrm{OH}(18)$.

All PD patients who underwent arterial blood sampling at the time of ${ }^{18} \mathrm{~F}-\mathrm{DA}$ scanning were off levodopa, carbidopa, and entacapone; and their arterial plasma DOPA levels were within the normal range. We presumed that abnormalities of sympathetic noradrenergic function observed in the myocardium were also found in extracardiac organs; however, $\mathrm{PD}-\mathrm{No}-\mathrm{OH}$ often entails low myocardial ${ }^{18} \mathrm{~F}-\mathrm{DA}$-derived radioactivity, despite neurochemical evidence of approximately normal extracardiac innervation (31). Most of the PD-No-OH patients were outpatients and did not undergo arterial catheterization or else underwent arterial catheterization as part of ${ }^{18} \mathrm{~F}-\mathrm{DOPA}$ scanning; only one PD-No$\mathrm{OH}$ patient underwent arterial catheterization as part of ${ }^{18} \mathrm{~F}-\mathrm{DA}$ scanning. We are planning neuroimaging and neurochemistry studies of additional PD-No-OH patients to test the hypothesis that PD-No-OH with cardiac sympathetic denervation but intact extracardiac innervation is associated with normal arterial ${ }^{18} \mathrm{~F}$-DOPAC responses. If so, this would be an "exception that proves the rule" in terms of the link between catecholaminergic denervation and decreased vesicular sequestration in Lewy body diseases. That is, patients with intact extracardiac innervation should have normal arterial ${ }^{18} \mathrm{~F}$-DOPAC responses, regardless of whether they have neuroimaging evidence for decreased cardiac innervation.

The $\mathrm{PD}+\mathrm{OH}$ group averaged about a decade older than the other groups, raising the possibility of age mismatching as a confounding variable. ANCOVA was conducted for each of the main dependent variables: neuronal uptake, rate of loss of intra-neuronal catechol- 
A
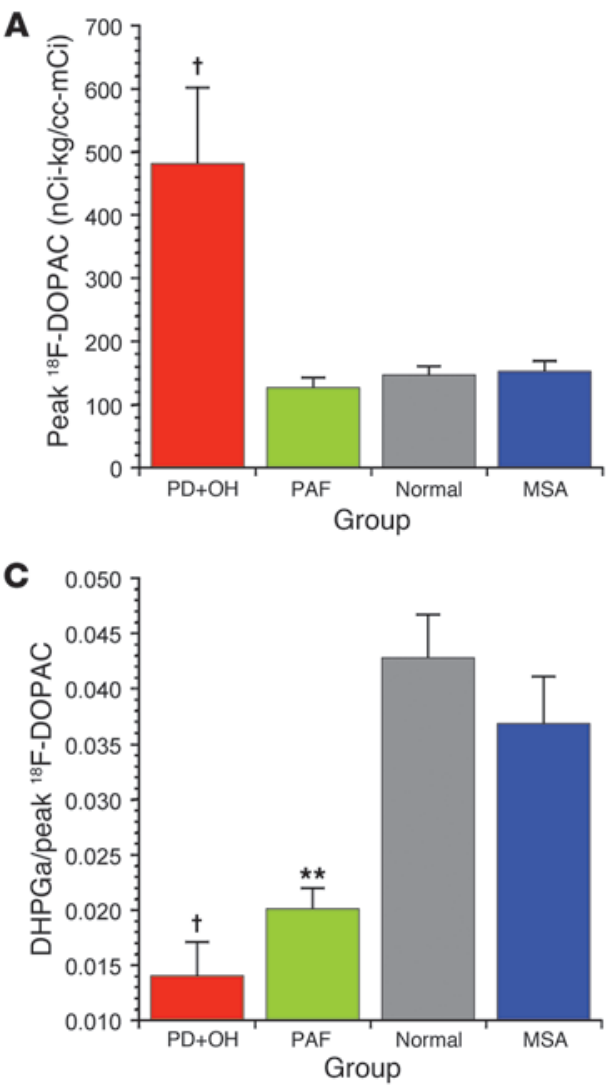

B

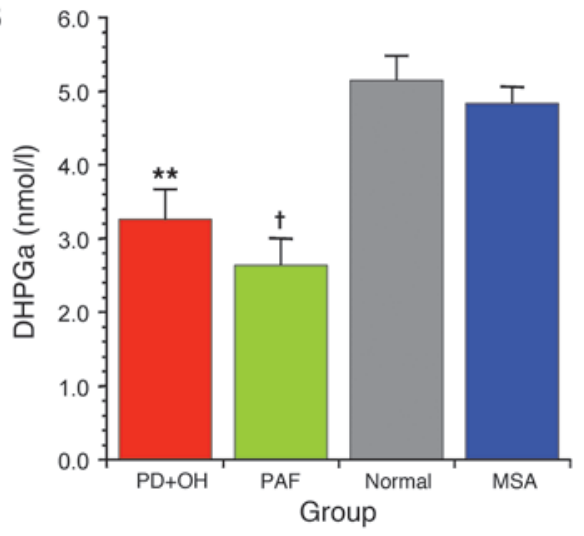

D

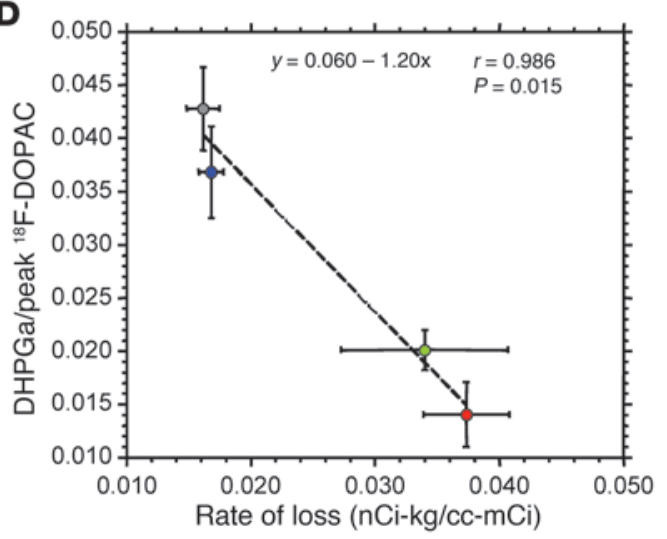

Figure 7

Intra-neuronal metabolism and overall vesicular uptake of ${ }^{18} \mathrm{~F}-\mathrm{DA}$. (A) Mean $( \pm \mathrm{SEM})$ peak arterial plasma concentrations of ${ }^{18} \mathrm{~F}-\mathrm{DOPAC}$. (B) DHPGa concentrations. (C) Mean values for whole-body vesicular uptake index (DHPGa/peak ${ }^{18}$ F-DOPAC). (D) Scatter plot of whole-body vesicular uptake index versus mean rate of loss of myocardial radioactivity. Red, PD+OH; blue, MSA; green, PAF; gray, normal controls subjects. ${ }^{\dagger} P<0.001,{ }^{* *} P<0.01$ compared with normal.

amines, and vesicular uptake index. For the rate of loss of intraneuronal catecholamines and for vesicular uptake, group $x$ age interactions were nonsignificant. For neuronal uptake, a significant group $\times$ age interaction term was obtained due to a positive correlation between 8-minute radioactivity and age in the normal group. This was consistent with our previous report that, among healthy individuals, myocardial ${ }^{18} \mathrm{~F}-\mathrm{DA}$-derived radioactivity increases with age (32); however, this would produce an effect in the direction opposite to that observed in our study. The group $\times$ age interaction term was not statistically significant when the ANCOVA for 8 -minute radioactivity was repeated for the patient groups only, and the post-hoc tests confirmed decreased neuronal uptake in the groups with Lewy body diseases compared with the MSA group. Therefore, although the patient groups differed in mean age, this did not detract from the main conclusions of the study.

Pathogenesis of denervation by cytosolic DA. Decreased VMAT activity could represent an underlying molecular mechanism contributing to catecholaminergic denervation in Lewy body disease pathogenesis. With ongoing catecholamine biosynthesis and vesicular leakage, decreased vesicular sequestration produces cytosolic catecholamines that are converted to toxic products by spontaneous autooxidation to quinones $(33,34)$ or enzymatic conversion to catecholaldehydes $(33,35,36)$. Moreover, cytosolic DA can interact with calcium and $\alpha$-synuclein to destroy substantia nigra neurons (37).
MAO can act on dopamine to produce dihydroxyphenylacetaldehyde (DOPAL), a catecholaldehyde that potently oligomerizes and aggregates $\alpha$-synuclein (38). Lipid peroxidation products interfere with detoxification of DOPAL (39) by inhibiting aldehyde dehydrogenase and aldehyde reductase (40), stimulating a potentially deadly positive feedback loop. Consistent with a pathogenetic role of catecholaldehydes in Lewy body diseases, a recent postmortem study noted a high ratio of DOPAL/DA in the putamen of patients with end-stage PD (41). In the present study, increased production of ${ }^{18} \mathrm{~F}$-DOPAC from cytosolic ${ }^{18} \mathrm{~F}-\mathrm{DA}$ implies increased production of the catecholaldehyde ${ }^{18} \mathrm{~F}-\mathrm{DOPAL}$ as the obligate intermediate metabolite.

Reserpine, a VMAT antagonist, depletes catecholamine stores in the brain and heart (42), produces decreased locomotion and other features reminiscent of PD (43), and evokes apoptosis of striatal neurons by a glutamate-dependent process (44). Mice with low type 2 VMAT have motor and non-motor manifestations similar to those in PD (45). Moreover, inhibition of vesicular sequestration augments the toxicity of a variety of agents such as 1-methyl-4-phenyl-1,2,3,6-tetrahydropyridine $(46,47)$ and 6 -hydroxydopamine (48). Conversely, the pesticide and complex I inhibitor rotenone inhibits vesicular uptake $(49,50)$, increases production of DOPAL (51), and evokes apoptosis via oxidation of cytosolic dopamine (52). 


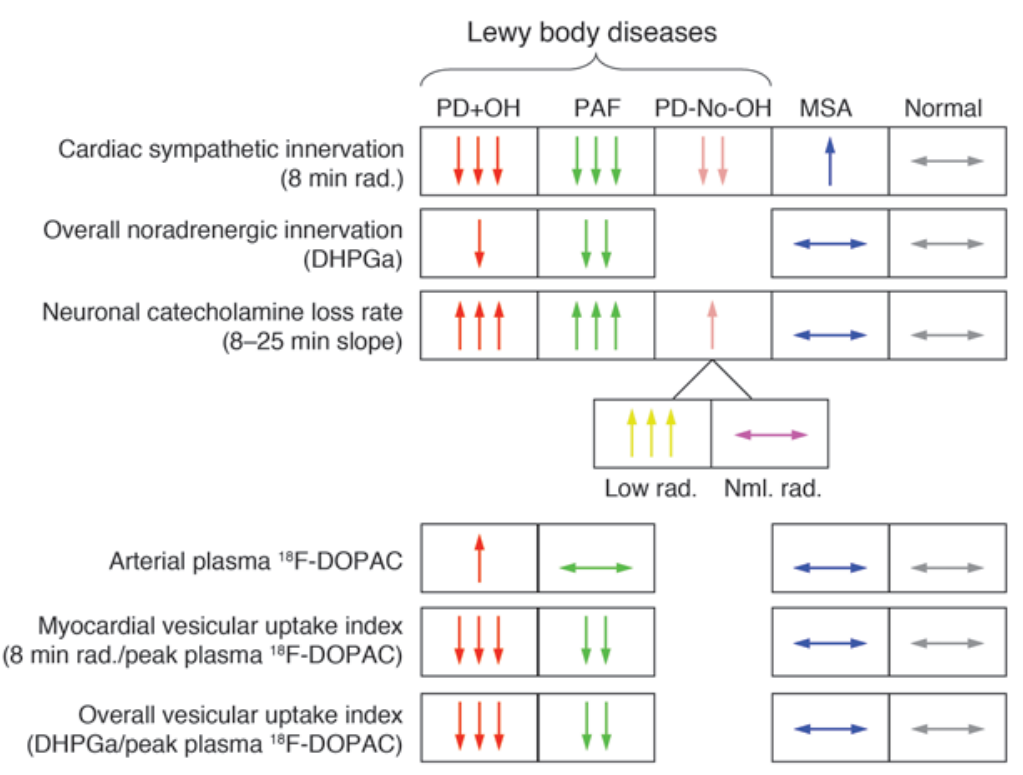

\section{Figure 8}

Summary of findings. PD+OH and PAF were associated with markedly decreased cardiac sympathetic innervation, PD-No-OH with less severe but significantly decreased innervation, and MSA with normal innervation. The $\mathrm{PD}+\mathrm{OH}, \mathrm{PAF}$, and $\mathrm{PD}-\mathrm{No}-\mathrm{OH}$ Low rad. groups had accelerated loss of radioactivity, whereas the PDNo-OH Nml. rad. and MSA groups had normal loss. The PD+OH and PAF groups had elevated ${ }^{18} \mathrm{~F}$-DOPAC after normalizing for initial myocardial radioactivity or for overall noradrenergic innervation (DHPGa). The findings are consistent with the concept that decreased vesicular uptake is associated with accelerated loss of intraneuronal catecholamines in Lewy body diseases.
Clinical significance. Given the above, there are several potential routes by which decreased VMAT activity could result in the catecholamine depletion that produces the major clinical manifestations of Lewy body diseases. Clinical laboratory findings of accelerated loss of ${ }^{18} \mathrm{~F}$-DA-derived radioactivity and decreased vesicular uptake may also be useful in the differential diagnosis of $\mathrm{PD}+\mathrm{OH}$ versus MSA. Similar tests may help in identifying $\alpha$-synucleinopathy in patients with dementia or other symptoms or signs of central neurodegeneration. Therapeutically, drugs targeted to increase the efficiency of VMAT function may have utility in the treatment or prevention of catecholaminergic neurodegeneration in Lewy body disorders.

\section{Methods}

Subjects. Patients were referred to the NIH and carried an admission diagnosis of PD, MSA, or PAF. Categorization in terms of occurrence of $\mathrm{OH}$ and diagnoses of $\mathrm{PD}, \mathrm{MSA}$, or PAF were based on previously published consensus criteria (53) supplemented by data about plasma levels of catechols (18). MSA patients were included regardless of classification in terms of parkinsonian, cerebellar, or mixed subtypes. In all patients with $\mathrm{OH}$, the $\mathrm{OH}$ was determined to be neurogenic because of abnormal responses of beat-to-beat blood pressure associated with the Valsalva maneuver (54) or attenuated orthostatic increments in plasma norepinephrine levels (55). Clinical characteristics of the patients are shown in Table 1.

The study included $37 \mathrm{PD}+\mathrm{OH}, 38 \mathrm{PD}-\mathrm{No}-\mathrm{OH}, 59 \mathrm{MSA}$, and $18 \mathrm{PAF}$ patients and 46 healthy controls. Arterial plasma levels of ${ }^{18} \mathrm{~F}-\mathrm{DOPAC}$ were measured in subgroups of $\mathrm{PD}+\mathrm{OH}(n=11), \mathrm{PAF}(n=7), \mathrm{MSA}(n=23)$, and control subjects $(n=29)$.

Plasma ${ }^{18} \mathrm{~F}$-DOPAC. Blood for assays of ${ }^{18} \mathrm{~F}-\mathrm{DOPAC}$ was drawn via an indwelling brachial arterial catheter. Plasma catechols including ${ }^{18} \mathrm{~F}$-DOPAC were assayed by batch alumina extraction followed by liquid chromatography with electrochemical detection, as described previously $(9,56)$. The concentration, in $\mathrm{pg} / \mathrm{ml}$, was converted to $\mathrm{nCi}-\mathrm{kg} / \mathrm{cc}-\mathrm{mCi}$ based on the specific activity of ${ }^{18} \mathrm{~F}-\mathrm{DA}$ at the time of injection and the dose of radioactivity in $\mathrm{mCi}$ per kg body mass. Individual values for septal radioactivity at 8 minutes divided by peak ${ }^{18} \mathrm{~F}-\mathrm{DOPAC}$ were used to provide an index of vesicular sequestration of cytosolic ${ }^{18} \mathrm{~F}-\mathrm{DA}$. An alternative measure of vesicular uptake based on the relationship between plasma ${ }^{18} \mathrm{~F}-\mathrm{DOPAC}$ and plasma DHPG was calculated as DHPGa divided by peak arterial ${ }^{18} \mathrm{~F}-\mathrm{DOPAC}$ to provide an index of vesicular sequestration in the body as a whole.

Data analysis and statistics. For each subject, we measured the concentration of myocardial radioactivity at 8 minutes after initiation of ${ }^{18} \mathrm{~F}-\mathrm{DA}$ administration as a measure of neuronal uptake. As a measure of loss of intra-neuronal catecholamine, we used the slope of the monoexponential line of best fit for the relationship of the $\log$ of ${ }^{18} \mathrm{~F}-\mathrm{DA}$-derived activity with time during the 8 - to 25 -minute period after injection. In a small number of subjects in whom radioactivity did not decrease during this interval, the slope data were excluded. The PD-No-OH group was stratified into two subgroups, one with low ${ }^{18} \mathrm{~F}-\mathrm{DA}$-derived activity (less than 5,000 $\mathrm{nCi}-\mathrm{kg} / \mathrm{cc}-\mathrm{mCi}$, about 2 SDs below the normal mean, in the frame at 8 minutes after initiation of ${ }^{18} \mathrm{~F}-\mathrm{DA}$ administration (PD-No-OH Low rad.) and one with normal radioactivity (PD-No-OH Nml. rad.), to test whether the two subgroups differed in mean slopes.

All clinical, neuroimaging, and neurochemical values were expressed as mean \pm 1 SEM. Mean values for uptake and subsequent decline of ${ }^{18} \mathrm{~F}-\mathrm{DA}-$ derived radioactivity and for vesicular uptake indices were compared across groups by factorial analysis of variance, with post-hoc group comparisons using the Fisher's protected least significant difference test. The graphics and statistical package was KaleidaGraph 4.01 (Synergy Software). Mean values in two subject groups (e.g., $\mathrm{PD}+\mathrm{OH}$ vs. MSA) were compared using independent means 2-tailed $t$ tests. Pearson correlation coefficients were calculated for scatter plots (e.g., relating slopes with 8-minute radioactivity). For frequency comparisons between groups, $\chi^{2}$ was calculated. A $P$ value less than 0.05 defined statistical significance.

Since the $\mathrm{PD}+\mathrm{OH}$ group was found to be substantially older than the other groups, we applied a regression approach to assess age as a possible confounding factor in the study. We carried out ANCOVAs (StatView 5.0.1, SAS Institute Inc.) for each of the main dependent variables: neuronal uptake (represented by 8 -minute myocardial ${ }^{18} \mathrm{~F}-\mathrm{DA}$-derived radioactivity), rate of loss of intra-neuronal catecholamines (represented by the slope of mono-exponential decline in radioactivity between 8 and 25 minutes), and the IVT (represented by 8 -minute radioactivity divided by peak arterial ${ }^{18} \mathrm{~F}$-DOPAC). Each ANCOVA included diagnostic group as the factor and age as the covariate.

Study approval. The Intramural Research Board of the NINDS at the NIH approved the protocols for this study. All subjects gave informed written consent before the procedures. 


\section{Acknowledgments}

This research was supported by the Intramural Research Program of the NIH, NINDS. Tereza Jenkins coordinated patient travel. Sandra Pechnik assisted with clinical procedures and scheduling. Basil Eldadah and Richard Imrich served as postdoctoral fellows when the work was performed.
Received for publication January 13, 2011, and accepted in revised form May 12, 2011.

Address correspondence to: David S. Goldstein, Clinical Neurocardiology Section, NINDS, NIH, 10 Center Drive MSC-1620, Building 10 Room 5N220, Bethesda, Maryland 20892-1620, USA. Phone: 301.496.2103; Fax: 301.402.0180. E-mail: goldsteind@ninds.nih.gov.
1. Kaufmann H, Goldstein DS. Dysautonomia in Parkinson disease. In Aminoff MJ, Boller F, Swaab DF, eds. Handbook of Clinical Neurology. New York, New York, USA: Elsevier; 2007:343-363.

2. Amino T, Orimo S, Takahashi A, Uchihara T, Mizusawa H. Profound cardiac sympathetic denervation occurs in Parkinson disease. Brain Pathol. 2005;15(1):29-34.

3. Goldstein DS, Orimo S. Cardiac sympathetic neuroimaging: summary of the First International Symposium. Clin Auton Res. 2009;19(3):137-148.

4. Goldstein DS. Cardiac denervation in patients with Parkinson disease. Cleve. Clin. J. Med. 2007; 74(suppl 1):S91-S94.

5. Goldstein DS, et al. Cardiac sympathetic denervation preceding motor signs in Parkinson disease. Clin Auton Res. 2007;17(2):118-121.

6. Dickson DW, et al. Evidence that incidental Lewy body disease is pre-symptomatic Parkinson's disease. Acta Neuropathol. 2008;115(4):437-444.

7. Sossi V, de la Fuente-Fernandez R, Schulzer M, Troiano AR, Ruth TJ, Stoessl AJ. Dopamine transporter relation to dopamine turnover in Parkinson's disease: a positron emission tomography study. Ann Neurol. 2007;62(5):468-474.

8 . Sossi $\mathrm{V}$, et al. Increase in dopamine turnover occurs early in Parkinson's disease: evidence from a new modeling approach to PET 18 F-fluorodopa data. J Cereb Blood Flow Metab. 2002;22(2):232-239.

9. Goldstein DS, Holmes C. Metabolic fate of the sympathoneural imaging agent 6-[18F]fluorodopamine in humans. Clin Exp Hypertens. 1997;19(1-2):155-161.

10. Goldstein DS, Katzper M, Linares OA, Kopin IJ Kinetic model for the fate of the sympathoneural imaging agent 6 -[18F]fluorodopamine in the human heart: a novel means to assess cardiac sympathetic neuronal function. Naunyn-Schmiedebergs Arch Pharmacol. 2002;365(1):38-49.

11. Chang PC, Szemeredi K, Grossman E, Kopin IJ, Goldstein DS. Fate of tritiated 6-fluorodopamine in rats: a false neurotransmitter for positron emission tomographic imaging of sympathetic innervation and function. J Pharmacol Exp Ther. 1990; 255(2):809-817.

12. Eisenhofer G, et al. Neuronal uptake and metabolism of 2- and 6-fluorodopamine: false neurotransmitters for positron emission tomographic imaging of sympathetically innervated tissues. J Pharmacol Exp Ther. 1989;248(1):419-427.

13. Goldstein DS, et al. Positron emission imaging of cardiac sympathetic innervation and function using 18F-6-fluorodopamine: effects of chemical sympathectomy by 6-hydroxydopamine. J Hypertens. 1991;9(5):417-423.

14. Kaufmann H, Hague K, Perl D. Accumulation of alpha-synuclein in autonomic nerves in pure autonomic failure. Neurology. 2001;56(7):980-981.

15. Tipre DN, Goldstein DS. Cardiac and extra-cardiac sympathetic denervation in Parkinson disease with orthostatic hypotension and in pure autonomic failure. J Nucl Med. 2005;46(11):1775-1781.

16. Shy GM, Drager GA. A neurological syndrome associated with orthostatic hypotension: a clinicalpathologic study. Arch Neurol. 1960;2:511-527.

17. Wakabayashi K, Yoshimoto M, Tsuji S, Takahashi $\mathrm{H}$. Alpha-synuclein immunoreactivity in glial cytoplasmic inclusions in multiple system atrophy. Neurosci Lett. 1998;249(2-3):180-182.

18. Goldstein DS, Holmes C, Sharabi Y, Brentzel S,
Eisenhofer G. Plasma levels of catechols and metanephrines in neurogenic orthostatic hypotension. Neurology. 2003;60(8):1327-1332.

19. Goldstein DS, Eisenhofer G, Stull R, Folio CJ, Keiser HR, Kopin IJ. Plasma dihydroxyphenylglycol and the intraneuronal disposition of norepinephrine in humans. J Clin Invest. 1988;81(1):213-222.

20. Orimo S, et al. Sympathetic cardiac denervation in Parkinson's disease and pure autonomic failure but not in multiple system atrophy. J Neurol Neurosurg Psychiatry. 2002;73(6):776-777.

21. Hague K, Lento P, Morgello S, Caro S, Kaufmann $\mathrm{H}$. The distribution of Lewy bodies in pure autonomic failure: autopsy findings and review of the literature. Acta Neuropathol. 1997;94(2):192-196.

22. Goldstein DS, et al. Patterns of plasma levels of catechols in neurogenic orthostatic hypotension. Ann Neurol. 1989;26(4):558-563.

23. Mosharov EV, et al. Alpha-synuclein overexpression increases cytosolic catecholamine concentration. J Neurosci. 2006;26(36):9304-9311.

24. Guo JT, Chen AQ, Kong Q, Zhu H, Ma CM, Qin C. Inhibition of vesicular monoamine transporter-2 activity in alpha-synuclein stably transfected $\mathrm{SH}$ SY5Y cells. Cell Mol Neurobiol. 2008;28(1):35-47.

25. Volles MJ, Lansbury PT Jr. Vesicle permeabilization by protofibrillar alpha-synuclein is sensitive to Parkinson's disease-linked mutations and occurs by a pore-like mechanism. Biochemistry. 2002; 41(14):4595-4602.

26. Okamura $\mathrm{N}$, et al. In vivo measurement of vesicular monoamine transporter type 2 density in Parkinson disease with (18)F-AV-133. J Nucl Med. 2010; 51(2):223-228

27. Sala G, et al. Vesicular monoamine transporter 2 mRNA levels are reduced in platelets from patients with Parkinson's disease. J Neural Transm. 2010; 117(9):1093-1098.

28. Hardwick JC, Ehrlich YH, Hendley ED. Extracellular ATP stimulates norepinephrine uptake in PC12 cells. J Neurochem. 1989;53(5):1512-1518.

29. Volz TJ, Hanson GR, Fleckenstein AE. Measurement of kinetically resolved vesicular dopamine uptake and efflux using rotating disk electrode voltammetry. J Neurosci Methods. 2006;155(1):109-115.

30. Xie T, Ho SL, Li LS, Ma OC. G/A1947 polymorphism in catechol-O-methyltransferase (COMT) gene in Parkinson's disease. Mov Disord. 1997; 12(3):426-427.

31. Goldstein DS, et al. Neurocirculatory abnormalities in Parkinson disease with orthostatic hypotension: independence from levodopa treatment. Hypertension. 2005;46(6):1333-1339.

32. Li ST, Holmes C, Kopin IJ, Goldstein DS. Agingrelated changes in cardiac sympathetic function in humans, assessed by $6-18 \mathrm{~F}$-fluorodopamine PET scanning. J Nucl Med. 2003;44(1):1599-1603.

33. Berman SB, Hastings TG. Dopamine oxidation alters mitochondrial respiration and induces permeability transition in brain mitochondria: implications for Parkinson's disease. J Neurochem. 1999; 73(3):1127-1137.

34. Creveling CR. The Role of Catechol Quinone Species in Cellular Toxicity. Johnson City, Tennessee, USA: FP Graham Publishing Co.; 2000

35. Burke WJ, et al. Neurotoxicity of MAO metabolites of catecholamine neurotransmitters: role in neurodegenerative diseases. Neurotoxicology. 2004; 25(1-2):101-115.
36. Hermida-Ameijeiras A, Mendez-Alvarez E, Sanchez-Iglesias S, Sanmartin-Suarez C, Soto-Otero R. Autoxidation and MAO-mediated metabolism of dopamine as a potential cause of oxidative stress: role of ferrous and ferric ions. Neurochem Int. 2004; 45(1):103-116.

37. Mosharov EV, et al. Interplay between cytosolic dopamine, calcium, and alpha-synuclein causes selective death of substantia nigra neurons. Neuron. 2009;62(2):218-229.

38. Burke WJ, et al. Aggregation of alpha-synuclein by DOPAL, the monoamine oxidase metabolite of dopamine. Acta Neuropathol. 2008;115(2):193-203.

39. Rees JN, Florang VR, Anderson DG, Doorn JA. Lipid peroxidation products inhibit dopamine catabolism yielding aberrant levels of a reactive intermediate. Chem Res Toxicol. 2007;20(10):1536-1542.

40. Jinsmaa Y, Florang VR, Rees JN, Anderson DG, Strack S, Doorn JA. Products of oxidative stress inhibit aldehyde oxidation and reduction pathways in dopamine catabolism yielding elevated levels of a reactive intermediate. Chem Res Toxicol. 2009;22(5):835-841.

41. Goldstein DS, Sullivan P, Holmes C, Kopin IJ, Basile MJ, Mash DC. Catechols in post-mortem brain of patients with Parkinson disease. EurJ Neurol. 2011;18(5):703-710.

42. Wakade AR. A comparison of rates of depletion and recovery of noradrenaline stores of peripheral and central noradrenergic neurones after reserpine administration: importance of neuronal activity. $\mathrm{Br}$ J Pharmacol. 1980;68(1):93-98.

43. Carlsson A. Biochemical and pharmacological aspects of Parkinsonism. Acta Neurol Scand Suppl. 1972;51:11-42.

44. Mitchell IJ, et al. Glutamate-induced apoptosis results in a loss of striatal neurons in the parkinsonian rat. Neuroscience. 1994;63(1):1-5.

45. Taylor TN, et al. Nonmotor symptoms of Parkinson's disease revealed in an animal model with reduced monoamine storage capacity. J Neurosci. 2009;29(25):8103-8113.

46. Gainetdinov RR, et al. Increased MPTP neurotoxicity in vesicular monoamine transporter 2 heterozygote knockout mice. J Neurochem. 1998;70(5):1973-1978.

47. Speciale SG, Liang CL, Sonsalla PK, Edwards RH, German DC. The neurotoxin 1-methyl-4-phenylpyridinium is sequestered within neurons that contain the vesicular monoamine transporter. Neuroscience. 1998;84(4):1177-1185.

48. Sun M, et al. Coexpression of tyrosine hydroxylase, GTP cyclohydrolase I, aromatic amino acid decarboxylase, and vesicular monoamine transporter 2 from a helper virus-free herpes simplex virus type 1 vector supports high-level, long-term biochemical and behavioral correction of a rat model of Parkinson's disease. Hum Gene Ther. 2004;15(12):1177-1196.

49. Watabe M, Nakaki T. Mitochondrial complex I inhibitor rotenone inhibits and redistributes vesicular monoamine transporter 2 via nitration in human dopaminergic SH-SY5Y cells. Mol Pharmacol. 2008; 74(4):933-940.

50. Sai Y, Wu Q, Le W, Ye F, Li Y, Dong Z. Rotenoneinduced PC12 cell toxicity is caused by oxidative stress resulting from altered dopamine metabolism. Toxicol In Vitro. 2008;22(6):1461-1468

51. Lamensdorf I, Eisenhofer G, Harvey-White J, Hayakawa Y, Kirk K, Kopin IJ. Metabolic stress in PC12 cells induces the formation of the endogenous 
dopaminergic neurotoxin, 3,4-dihydroxyphenylacetaldehyde. J Neurosci Res. 2000;60(4):552-558.

52. Liu HQ, Zhu XZ, Weng EQ. Intracellular dopamine oxidation mediates rotenone-induced apoptosis in PC12 cells. Acta Pharmacol Sin. 2005;26(1):17-26.

53. Kaufmann H. Consensus statement on the definition of orthostatic hypotension, pure autonomic failure and multiple system atrophy. Clin Auton Res.
1996;6(2):125-126.

54. Goldstein DS, Tack C. Noninvasive detection of sympathetic neurocirculatory failure. Clin Auton Res. 2000;10(5):285-291.

55. Ziegler MG, Lake CR, Kopin IJ. The sympatheticnervous-system defect in primary orthostatic hypotension. N Engl J Med. 1977;296(6):293-297.

56. Holmes C, Eisenhofer G, Goldstein DS. Improved assay for plasma dihydroxyphenylacetic acid and other catechols using high-performance liquid chromatography with electrochemical detection. Chromatogr B Biomed Appl. 1994;653(2):131-138.

57. Goldstein DS, Sewell L, Sharabi Y. Autonomic dysfunction in PD: a window to early detection? [published online ahead of print April 27, 2011]. J Neurol Sci. doi:10.1016/j.jns.2011.04.011. 